\title{
Studi Perencanaan Usaha Keripik Kaca Menggunakan Business Model Canvas
}

\author{
Ayuni Rizma Maulida ${ }^{\mathrm{a}, 1,{ }^{*}}$, Andre Geza Haryanto ${ }^{\mathrm{b}, 2}$ \\ ${ }^{\text {a b} U n i v e r s i t a s ~ P G R I ~ S e m a r a n g, ~ G e d u n g ~ P u s a t ~ L a n t a i ~ 3, ~ K a m p u s ~} 1$ Jl. Sidodadi Timur 24, Semarang 50124, Indonesia \\ ${ }^{1}$ ayuni.rizmamaulida@gmail.com*; ${ }^{2}$ kobongkasarong@gmail.com \\ * penulis korespondensi
}

\begin{abstract}
The business world needs a business plan that can help entrepreneurs prepare everything needed for the smooth running of their business. This business plan can be made in the form of a business plan. One business plan model that has many advantages is the Business Model Canvas. The purpose of writing this article is to find out what needs to be considered in making a business plan using the Business Model Canvas. The results of the literature review show that using the Business Model Canvas business planning becomes clearer and more focused. The glass chip business, which is an example in the application of the canvas business model, is becoming more focused and clear. Therefore, in making a business model, the canvas has 9 important components, including Customer Segment, Value Propositions, Channels, Customer Relationships, Revenue Streams, Key Activities, Key Partnerships, Key Resources and Cost Structures that need to be considered and structured clearly to help run the business.
\end{abstract}

Keywords: business, Business Model Canvas, business plan, glass chips, planning

\section{ABSTRAK}

Dunia usaha memerlukan suatu perencanaan usaha yang dapat membantu wirausahawan menyiapkan segala sesuatu yang dibutuhkan untuk kelancaran usahanya. Perencanaan usaha ini dapat dibuat dalam bentuk business plan. Salah satu model business plan yang banyak memiliki keuntungan yaitu Business Model Canvas. Tujuan dari penulisan artikel ini adalah untuk mengetahui apa saja yang perlu diperhatikan untuk membuat perencanaan usaha menggunakan Business Model Canvas. Hasil dari penelaahan pustaka menunjukkan dengan menggunakan Business Model Canvas perencanaan usaha menjadi lebih jelas dan terarah. Usaha keripik kaca yang menjadi contoh dalam penerapan Business Model Canvas ini menjadi lebih terarah dan jelas. Oleh karena itu dalam pembuatan Business Model Canvas memiliki 9 komponen penting diantaranya Customer Segment, Value Propositions, Channel, Customer Relationship, Revenue Streams, Key Activities, Key Partnership, Key Resources dan Cost Structure yang perlu diperhatikan dan disusun dengan jelas agar membantu kelancaran usaha.

Kata Kunci: Business Model Canvas, business plan, keripik kaca, perencanaan, usaha

\section{Pendahuluan}

Dunia saat ini menunjukkan perkembangan zaman yang pesat. Jika kita tidak mengikutinya maka kita akan tertinggal. Di zaman yang serba modern ini muncul banyak usaha baru yang sekarang ini menjamur dimana-mana. Kewirausahaan menjadi bidang yang sangat menarik untuk ditekuni, karena bidang ini telah berhasil menyelamatkan bangsa Indonesia dari keterpurukkan ekonomi. Bidang kewirausahaan telah menjadi solusi alternatif lapangan kerja baru, di tengah semakin langkanya lapangan kerja baru. Bahkan 
selama 10 tahun ini lapangan kerja baru di sektor ini telah menyerap 2,5 juta calon tenaga kerja. Jumlah ini sangat fantastis mengingat Indonesia sebagai negara yang terkena imbas krisis moneter secara global, masalah ketenagakerjaan menjadi beban yang sangat berat yang dihadapi pemerintah saat ini (Kasmir, 2006). Untuk mendirikan usaha tentunya kita perlu membuat suatu rancangan usaha. Rancangan usaha adalah suatu gambaran mengenai detail usaha yang akan dijalankan. Rancangan usaha ini dibuat untuk mencapai keberhasilan usaha dapat dipakai suatu pendekatan yaitu meliputi pencapaian tujuan, pendekatan sistem, pendekatan konstituensi strategis, dan pendekatan nilai-nilai bersaing. Pendekatan pencapaian tujuan menyebutkan bahwa keberhasilan usaha harus dinilai sehubungan dengan pencapaian tujuan yaitu mendapatkan laba atau keuntungan yang merupakan selisih antara harga jual dengan biaya produksi (Suryana, 2009). Dengan perencanaan bisnis yang baik akan menjadikan peluang sukses lebih tinggi (Supriyanto, 2009), tanpa perencanaan yang baik perusahaan akan kehilangan sasaran (Kristianto, 2012).

Berwirausaha tidak cukup hanya berbekal keyakinan, namun diiperlukan perencanaan usaha (business plan). Menjalankan usaha khususnya usaha baru tidak mungkin tanpa ada rencana sebelumnya. Rencana harus ada betapa pun sederhananya secara tertulis. Perencanaan yang tidak tertulis pasti sudah ada dalam pikiran, yaitu suatu rekayasa secara sederhana tentang jawaban dari berbagai pertanyaan antara lain, usaha apa yang akan dibuka, mengapa memilih usaha tersebut, dimana lokasinya, siapa konsumennya, darimana sumber modal, dsb. Cara wirausaha baru seperti ini cenderung melaksanakan kegiatan trial and error atau coba-coba. Seandainya gagal mereka akan beralih ke usaha yang lain. Model seperti ini banyak dijumpai dalam masyarakat bisnis kita (Yildirim, 2012). Business plan merupakan sarana sistematis dalam mempertajam ide bisnis. Dengan bantuan business plan, ide-ide bisnis akan lebih terencana dan sistematis. Melalui pendekatan-pendekatan standar business plan, akan diketahui siapa saja pasar atau konsumen potensial, bagaimana proses pemasarannya, serta bagaimana proses operasional dari bisnis yang sedang dijalani. Dengan kata lain business plan merupakan dokumen tertulis yang harus direncanakan oleh pengusaha yang meliputi semua unsur yang relevan baik unsur eksternal dan internal dalam memulai usaha baru (Hisrich dan Peters, 2008).

Persaingan usaha yang sangat tinggi tentunya memacu semangat pelaku usaha atau wirausahawan untuk lebih meningkatkan produktivitas maupun sistem yang telah dimiliki. Persaingan bisnis semakin berat dan ketat, setiap perusahaan selalu dituntut untuk berkembang. Salah satu cara yang digunakan perusahaan atau pelaku usaha untuk dapat bersaing dan berkembang adalah menciptakan strategi-strategi yang baru. Namun strategi itu sendiri tidaklah cukup, perusahaan harus punya model bisnis yang kuat dan baik serta tepat pada perusahaan miliknya. Business Model Canvas (BMC) memiliki keunggulan dalam analisis model bisnis yaitu mampu mengambarkan secara sederhana dan menyeluruh terhadap kondisi suatu perusahaan saat ini berdasarkan segmen konsumen, value yang ditawarkan, jalur penawaran nilai, hubungan dengan pelangan, aliran pendapatan, aset vital, mitra kerja sama, serta struktur biaya yang dimiliki (Rainaldo et al., 2017). Oleh karena itu artikel ini disusun dengan tujuan untuk mengetahui apa saja hal-hal yang perlu diperhatikan dalam membuat perencanaan usaha menggunakan Business Model 
Canvas (BMC) ini serta contoh gambaran penerapan Business Model Canvas (BMC) dalam usaha keripik kaca.

\section{Metode Penelitian}

Metode penelitian yang dipakai yaitu mengumpulkan jurnal-jurnal atau studi kepustakaan mengenai Business Model Canvas (BMC). Setelah itu dipilah berdasarkan kualifikasi rumusan masalah yaitu mengenai lingkup Business Model Canvas (BMC). Langkah selanjutnya yaitu mereview studi kepustakaan yang sudah didapat. Setelah direview maka dituangkan ke dalam artikel ini. Untuk contoh penerapan Business Model Canvas (BMC) dalam usaha keripik kaca merupakan murni dari hasil pemikiran penulis dilihat dari ruang lingkup Business Model Canvas (BMC) yang didapat dari studi kepustakaan sebelumnya. Dapat dilihat judul artikel ini memuat studi tentang Business Model Canvas (BMC), sehingga yang dilakukan yaitu mencari referensi studi kepustakaan kemudian dikualifikasi dan dipilah selanjutnya direview apa saja yang perlu dituliskan dalam artikel ini.

\section{Hasil dan Pembahasan}

\subsection{Business Model Canvas}

Konsep model bisnis mulai ramai dibicarakan sejak tahun 1990-an ketika internet mulai banyak membahas tentang konteks model bisnis dalam sebuah perusahaan dan bagaimana perubahan lingkungan bisnis. Konsep model bisnis digunakan sebagai cara yang umum untuk menjelaskan bagaimana perusahaan berinteraksi dengan pemasok, mitra kerja, dan pelanggan, serta untuk menggambarkan dasar pemikiran tentang bagaimana organisasi menciptakan, memberikan, dan menangkap nilai (Gunawan, 2016). Buku yang berjudul "Business Model Generation" membuat suatu kerangka business model yang berbentuk kanvas dan terdiri dari sembilan kotak yang saling berkaitan. Kotak-kotak ini berisikan elemen-elemen penting yang menggambarkan bagaimana organisasi menciptakan nilai dan mendapatkan manfaat dari para pelanggannya (Osterwalder \& Pigneur, 2010).

Menurut penelitian Euis et al. (2014), Business Model Canvas (BMC) memiliki sembilan elemen penting dalam membantu mengidentifikasikan model bisnis pada KNM Fish Farm dan membantu untuk mengidentifikasi elemen-elemen yang memerlukan perbaikan untuk membantu keberlangsungan usaha di masa depan. Bisnis model kanvas juga dapat digunakan sebagai alat untuk memberikan usulan rancangan model bisnis yang baru yang akan diterapkan sebagai contoh salah satu unit usaha baru CV. OAG yang memproduksi keripik bayam (Rukka et al., 2018).

Dalam buku "Business Model Canvas: Penerapan di Indonesia" terdapat 9 elemen dasar yang memperhatikan bagaimana cara berfikir suatu organisasi baik itu profit maupun non profit seperti perpustakaan dalam meningkatkan kualitas layanan perpustakaan di dalam sebuah perguruan tinggi, serta dapat menghasilkan nilai dan menciptakan manfaat bagi para pelanggannya. Langkah pertama yang dilakukan dalam model bisnis kanvas adalah membuat hipotesis awal kemudian dikonfirmasikan kepada konsumen secara langsung dan tidak langsung (on line). Konfirmasi dilakukan dengan test the problem dan test the solution kepada konsumen dan penjualan produk (Blank dan Dorf, 2012). Elemen-elemen 
tersebut meliputi Customer Segment, Value Propositions, Channel, Customer Relationship, Revenue Streams, Key Activities, Key Partnership, Key Resources dan Cost Structure (Permana, 2013). Penjelasan elemen-elemen tersebut menurut (Wardhanie, 2017) antara lain: Customer Segments adalah masyarakat yang menggunakan jasa/produk dari organisasi dan mereka yang berkontribusi dalam memberikan penghasilan bagi organisasi. Segmentasi pelanggan juga dapat dipilah berdasarkan perilaku, umur, profesi, penghasilan dan geografi. Value Propositions merupakan satu keunikan yang menentukan mengapa produk atau jasa tersebut pantas dipilih oleh pelanggan. Hal ini memberi tawaran untuk memecahkan masalah pelanggan dan semaksimal mungkin memenuhi keinginan pelanggan. Channel, sebuah elemen seperti komunikasi, distribusi dan saluran penjualan yang menyatakan bagaimana cara organisasi berkomunikasi dengan pelanggan segmennya dan menyampaikan value proposition-nya (Gambar 3.1).

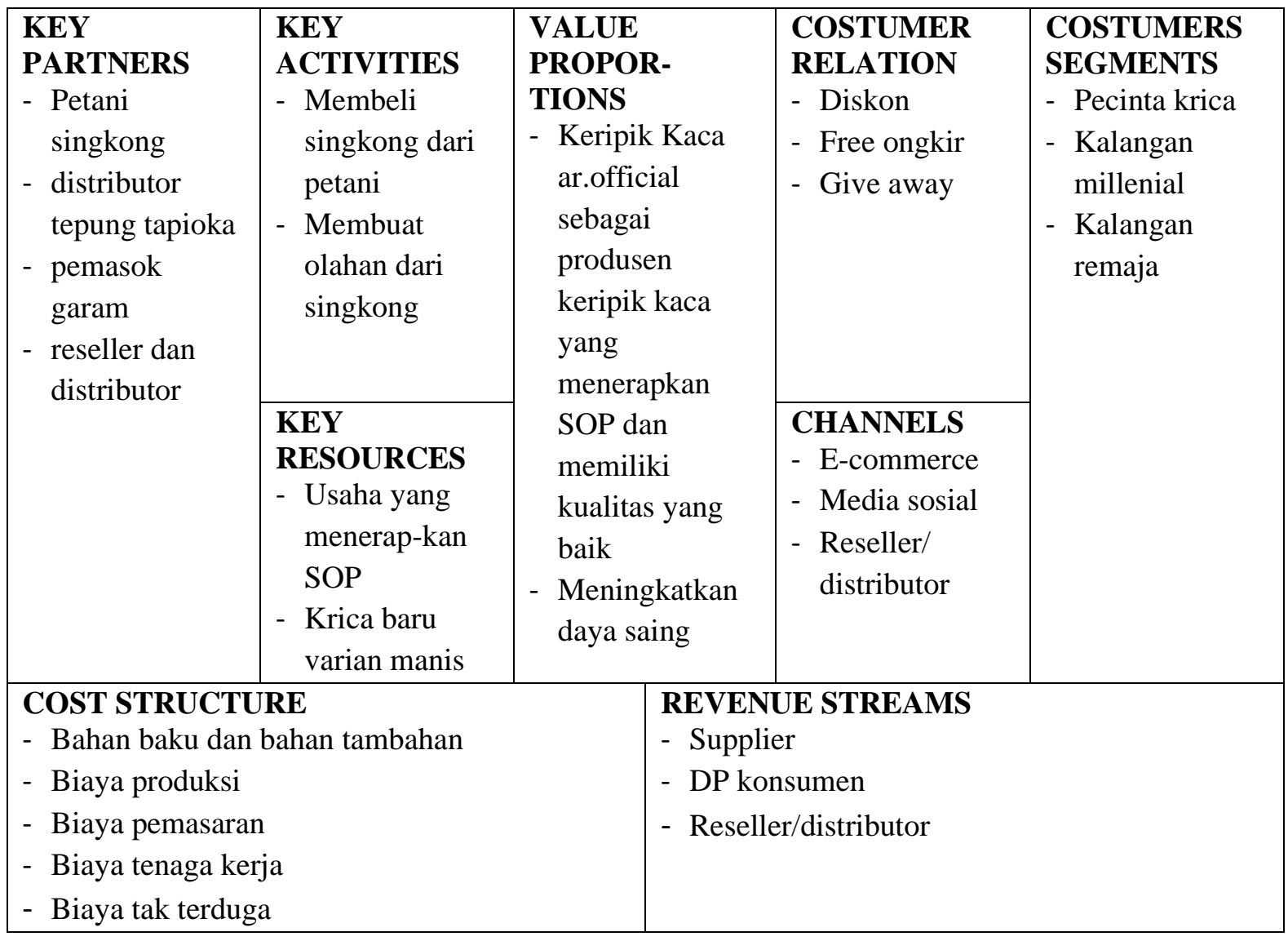

Gambar 1. Contoh Business Model Canvas Keripik Kaca

Customer Relationship, pembinaan hubungan dengan pelanggan, dengan tujuan untuk mendapatkan pelanggan baru dan mempertahankan pelanggan lama. Revenue Streams atau aliran dana masuk yang menggambarkan bagaimana organisasi memperoleh penghasilan berupa uang dari setiap customer segments. Aliran dana inilah yang membuat sebuah perusahaan tetap hidup atau survive. Key Resources menggambarkan aset-aset terpenting yang menentukan keberhasilan pengoperasian model bisnis, seperti bangunan, kendaraan, intelektual dan tenaga kerja. Key Activities merupakan kegiatan utama yang menunjang keberhasilan suatu model bisnis dalam mengirimkan value propotitions-nya kepada 
pelanggan. Key Partnership, suatu kesepakatan kerja sama bisnis yang diprakarsai secara sukarela antara dua atau lebih perusahaan untuk menyelesaikan proyek tertentu. Kerjasama ini dapat menimbulkan penghematan biaya, mengurangi resiko dan memperoleh sumber daya yang tidak dimiliki perusahaan. Cost Structure menggambarkan semua biaya yang muncul sebagai akibat dioperasikannya model bisnis ini guna mewujudkan value propotitions melalui channel, key resource, key activities yang tepat dan dapat diandalkan.

\subsection{Penerapan Business Model Canvas Dalam Usaha Keripik Kaca}

Krica atau keripik kaca adalah makanan yang terbuat dari adonan tepung tapioka yang ditambahkan air kemudian dipipihkan dan dijemur. Biasanya keripik kaca terbuat dari adonan tepung tapioka saja namun ada beberapa yang menambahkan potongan singkong kedalam adonan agar lebih enak dan lebih dapat teksturnya. Krica dapat pula disebut-sebut sebagai produk olahan yang berasal dari diversifikasi keripik singkong. Jika dilihat-lihat krica mirip dengan keripik singkong hanya saja penampilannya berbeda dan lebih tipis dibandingkan dengan keripik singkong. Meskipun dibuat dari adonan tepung tapioka dan air saja, namun krica ini memiliki rasa yang asin dan tekstur yang kriuk. Biasanya keripik kaca disajikan dengan berbagai topping atau bumbu pedas seperti bubuk cabai merah, bubuk cabai hijau, black paper dan sebagainya. Nama keripik kaca terinspirasi dari bentuk penampilan si keripik yang sangat tipis dan bening sehingga disebut dengan keripik kaca. Yang membedakan dengan keripik yang lain keripik kaca ini digoreng menggunakan minyak sedikit sehingga tidak mengembang hanya saja menghasilkan sensasi keriuk seperti keripik yang lain. Tekstur krica dan keripik singkong tentunya berbeda. Jika keripik singkong tebal maka krica ini tipis dan bening jika belum ditambahkan toping.

Bahan baku untuk pembuatan keripik kaca yaitu singkong, tepung tapioka, air dan garam. Singkong saya ambil langsung dari petani singkong. Tepung tapioka saya ambil dari distributor pertama pabrik tepung tapioka. Saya gunakan air dari PDAM. Kemudian untuk garam saya ambil dari pemasok garam. Bahan tambahan yang dibutuhkan untuk pembuatan keripik kaca yaitu bahanbahan yang dibutuhkan untuk membuat toping dan minyak goring untuk memasak krica yang sudah jadi. Toping pedas saya menggunakan cabai merah dan cabai hijau yang didapat dari petani cabai. Dan black paper saya membeli kemasan yang kiloan. Toping manis saya menggunakan milo, coklat bubuk, dan keju bubuk kiloan yang saya beli didistributor atau pemasok dipasar.

Konsep pemasaran yang digunakan dalam usaha keripik kaca ini adalah

1. Segmentasi (Geografis, demografis, psikografis)

- Segmen Geografi

Produk keripik kaca akan menjual diberbagai daerah sekitar kabupaten Pemalang terlebih dahulu karena tempat produksi akan ditempatkan dirumah saya. Ditinjau dari segmen geografi menurut saya keripik kaca dapat dikonsumsi dimana saja baik daerah pegunungan maupun didaerah pantai atau dataran rendah.

- Segmen Psikografi

Pada segi segmentasi psikografi, produk keripik kaca menghadirkan jenis varian produk baru yang berbeda dengan produk yang sudah ada dipasaran. Selain itu produk ini disesuaikan dengan kebutuhan dan keinginan konsumen. Salah satu 
produknya yaitu varian rasa manis yang terdiri dari toping milo, coklat, dan keju. Sasaran dari produk ini adalah konsumen yang tidak menyukai snack pedas.

- Segmen Demografi

Dalam segi demografi, ar.official mentargetkan segmen pasar yang terolong dalam kalangan millenial, baik itu laki-laki maupun perempuan dengan usia 20-30 tahun. Namun tidak menuntut kemungkinan kalangan remaja juga menyukai produk keripik kaca ini yaitu rentang usia 15-20 tahun.

2. Promotion

- Media promosi

Media promosi yang akan saya pilih yaitu media sosial dan blog. Media sosial yang digunakan meliputi whatsapp, instagram, dan facebook. Penggunaan media sosial ditujukan untuk memposting tentang produk krica yang saya produksi dan berbagai promosi yang ditawarkan. Blog yang saya gunakan akan saya kelola sedemikian rupa agar menjadi menarik dan seakan-akan blog ini merupakan store dari krica ar.official ini. Dengan berbagai media promosi ini diharapkan mampu membantu mengenalkan produk krica.

- Konsep promosi

Promosi yang akan saya lakukan yaitu memberikan diskon atau potongan harga pada event tertentu misalnya potongan jumat berkah sebanyak 5\%, potongan saat harnolnas, diskon akhir tahun. Promosi selanjutnya membebaskan biaya ongkos kirim dengan minimal pembelian tertentu, dengan bekerja sama dengan perusahaan ekspedisi tentunya kita akan mendapatkan kesempatan free ongkir dengan minimal pembelian tertentu, ini akan sangat menarik minat konsumen untuk membeli produk krica. Selanjutnya yaitu give away, dengan promosi give away ini kita bisa menjalin komunikasi interaktif dengan konsumen yaitu mengadakan lomba tertentu untuk mendapat suatu hadiah, tentunya sangat menarik konsumen.

Konsep promosi yang dipilih yaitu advertising dan personal selling. Advertising dipilih karena krica ini termasuk e-commerce sehingga diperlukan advertising diberbagai media online. Kemudian personal selling yaitu promosi yang dilakukan sumber daya manusia contohnya promosi dari mulut kemulut mulai dari kerabat hingga teman dekat saya mengenalkan bahwa saya memiliki produk krica dengan berbagai varian.

3. Price

Konsep penentuan harga yang saya pilih yaitu konsep penetapan harga berdasarkan keseimbangan antara jumlah total biaya keseluruhan dengan jumlah total penerimaan keseluruhan atau Break Even Point. Konsep ini dipilih karena mampu menyeimbangkan harga produksi total dan harga produk. Sedangkan strategi yang digunakan yaitu Product Life Cycle Pricing yang mana semua produk memiliki masa hidup. Suatu produk secara bertahap berkembang melalui tahapan yang berbeda dalam siklus: tahap pengenalan, pertumbuhan, kedewasaan, dan penurunan. Selama tahap pertumbuhan, saat penjualan sedang ramai, perusahaan kecil biasanya akan mempertahankan harga lebih tinggi. Misalnya, jika produk perusahaan unik atau berkualitas lebih tinggi daripada produk pesaing, pelanggan kemungkinan besar akan membayar harga yang 
lebih tinggi. Perusahaan yang memberi harga tinggi pada produknya dalam tahap pertumbuhan juga memungkin menembah teknologi baru yang banyak diminati.

Harga promo nantinya akan dikalkulasikan dengan harga normal. Misal potongan 5\% maka harga potongan 5\% yaitu harga normal dikurangi dengan harga normal dikali $5 \%$. Begitu juga dengan angka diskon yang berlaku.

4. Saluran Distribusi

- Penjualan langsung baik online atau offline

Penjualan langsung ini bisa dilakukan dengan COD langsung antara saya dan pembeli maupun kurir dengan pembeli atau bisa juga pembeli langsung datang ketempat produksi karena diada tempat etalase untuk memajang produk meskipun dirumah produksi.

- Distributor atau reseller

Saya akan bekerja sama dengan distributor maupun reseller untuk membantu saya dalam hal pemasaran langsung dengan konsumen. Nantinya mereka akan mengambil barang sesuai pemasanan dengan harga reseller. Cara bergabung menjadi reseller saya mudah yaitu awal gabung cukup membeli barang minimal agar mendapat harga reseller atau grosir.

Kelebihan dari usaha keripik kaca ini adalah menerapkan SOP yang sudah ditentukan. SOP tersebut antara lain:

1. SOP bahan mentah antara lain:

- Bagian bahan baku dan bahan tambahan mengecek secara berkala ketersediaan bahan

- Bagian bahan baku dan bahan tambahan mencatat segala persediaan yang sudah mulai menipis

- Bagian bahan baku dan bahan tambahan melaporkan persediaan stok kepada bagian pembukuan dan mengajukan penambahan stok jika ada yang menipis atau habis

- Bagian pembukuan melakukan pemesanan bahan baku dan tambahan kepada supplier

- Bagian bahan baku dan bahan tambahan mengecek kelengkapan dokumen yang diperlihatkan supplier saat bahan baku dan bahan tambahan datang sebelum diterima

- Setelah dicek dan dinyatakan aman sesuai dengan kualitas yang diinginkan maka bahan baku dan bahan tambahan tersebut baru diterima dan disimpan ditempat penyimpanan

2. SOP produksi antara lain:

- Bagian produksi melaksanakan tugasnya sesuai dengan jobdesk masing-masing

- Pengecekan alat dilakukan secara rutin sebelum dan sesuai dimulainya produksi

- Pembersihan alat dilakukan setelah selesai produk

- Sebelum produksi kelengkapan alat dan kebersihan alat dicek kembali

- Setiap mulai bekerja dicek lagi kelengkapan bahan dan formulasi yang digunakan

- Saat penjemuran pastikan waktunya pas agar mendapatkan kualitas krica yang tinggi

- Bagian pengemasan dicek lagi kemasan produk jangan sampai ada yang bocor, gambar tidak sesuai dan kemasan rusak

- Berat produk harus dipastikan sesuai dengan yang tercantum dalam kemasan 
3. SOP pemasaran antara lain:

- Sebelum dipasarkan pastikan dulu kemasan produk masih aman dan tidak ada yang rusak atau cacat

- Kurir mengecek pesanan konsumen agar tidak salah ataupun keliru sebelum dilakukan pengantaran

- Admin online pastikan bahwa yang diposting sudah ready stok atau minimal sedang dalam proses produksi sehingga saat konsumen memesan tidak membutuhkan waktu yang lama

\section{Kesimpulan}

Business Model Canvas ini memiliki keunggulan sehingga dapat memudahkan wirausahawan untuk memproyeksikan usahanya agar lebih jelas dan terarah. Usaha keripik kaca yang menjadi contoh dalam penerapan Business Model Canvas ini menjadi lebih terarah dan jelas. Oleh karena itu dalam pembuatan Business Model Canvas memiliki 9 komponen penting diantaranya Customer Segment, Value Propositions, Channel, Customer Relationship, Revenue Streams, Key Activities, Key Partnership, Key Resources dan Cost Structure yang perlu diperhatikan dan disusun dengan jelas agar membantu kelancaran usaha. BMC disarankan untuk diterapkan baik saat memulai rancangan usaha maupun untuk memperbaiki usaha yang sudah ada namun lebih disarankan untuk menggunakan BMC sedari menyusun rancangan usaha agar hasil yang dicapai maksimal.

\section{Pustaka}

Blank, S. dan Dorf, B. 2012. The Startup Owner's Manual' ${ }^{\mathrm{TM}}$ The Step-by-Step Guide for Building a Great Company. K and S Ranch Inc., K\&S Ranch Publishing Division, California.

Euis, S., Hubeis, S., dan Maulana, A. 2014. Analisis model bisnis pada KNM fish farm dengan pendekatan Business Model Canvas (BMC). Jurnal Sosek KP, 9 (2): 185194.

Gunawan, M. F. 2016. Perancangan Business Model Canvas sebagai alternative strategi bisnis budidaya ikan gurame (studi kasus pada ukm mitra mina desa Sridadi kecamatan Kalirejo Lampung Tengah). dilihat 1 Juni 2018. Retrieved from Http://digilib.unila.ac.id/21790/20/skripsi\%20tanpa\%20bab\%20pembahasan.pdf.

Hisrich, D. R., and Peters, M.P. 2008. Enterpreneurship. New York: McGraw Hill

Kasmir. 2006. Kewirausahaan. Jakarta : Rajawali Pers. Edisi Revisi.

Kristianto, D. 2012. Menyusun Business Plan dalam rangka Mengembangkan Usaha. Jurnal Ekonomi dan Kewirausahaan. 12 (1): 58-66.

Osterwalder, Alexander, \& Pigneur, Yves. 2010. Business Model Generation . John Wiley \& Sons, Inc., Hoboken, New Jersey.

Permana, D. J. 2013. Analisis peluang bisnis media cetak melalui pendekatan bisnis model canvas untuk menentukan strategi bisnis baru. Faktor exacta ISSN: 1979-276X, 6 (4), 309-319. 
Rainaldo M., Wibawa, B.M., Rahmawati, Y. 2017. Analisis Business Model Canvas pada operator jasa online ride-sharing (Studi kasus Uber di Indonesia). Jurnal Sains dan Seni ITS, 6 (2): 235-239.

Rukka, M.R., Busthanul, N., dan Fatonny, N. 2018. Strategi pengembangan bisnis dengan pendekatan busines model kanvas (Studi Kasus Pada CV. OAG di Kota Makasar, Sulawesi Selatan). Jurnal Sosial Ekonomi Pertanian, 14 (1) : 41-54.

Supriyanto. 2009. Business plan sebagai langkah awal memulai usaha. Jurnal Ekonomi \& Pendidikan, 6 (1): 73-83.

Suryana. 2009. Mompreneurship. Jakarta : Andi Offset

Wardhanie,A. P. 2017. Buku ajar model bisnis. Surabaya: PT. Revka petra media

Yildirim, N., Askun, O. B. 2012. Entrepreneurship Intentions of Public Universitiesin Turkey: Going Beyond Education and Research? 8th International Strategic Management Conference, Procedia - Social and Behavioral Science. 